\title{
Flexibility in Learning and Teaching Styles in an Accounting Course. "Deming Towards Kolb"
}

\author{
Ida Verna ${ }^{1}$ \\ ${ }^{1}$ Department of Management and Business Administration, "G. d'Annunzio" University of Chieti-Pescara, V.le \\ Pindaro, n. 42, 65127-Pescara, Italy \\ Correspondence: Ida Verna, Department of Management and Business Administration, "G. d'Annunzio" \\ University of Chieti-Pescara, V.le Pindaro, n. 42, 65127-Pescara, Italy.
}

Received: August 24, 2020

doi:10.5539/ibr.v13n11p77

\author{
Accepted: October 9, 2020 \\ Online Published: October 23, 2020 \\ URL: https://doi.org/10.5539/ibr.v13n11p77
}

"A well-made head is better than a well-filled head" Michel De Montaigne

\begin{abstract}
This work aims to investigate the effect of a holistic approach to teaching on both the educator's learning and teaching styles and on student performance. To this end, an experimental holistic approach was adopted, L'Ascolto $^{\circledR}$, which uses the Deming PDCA cycle for the design (Plan), management (Do), evaluation (Check) and improvement (Act) of teaching processes. The aim is to encourage educators to "train" their flexibility in learning by following the Kolb Experiential Learning Cycle. The paper is presented as an original study aimed at empirically examining the effects of an experimental holistic approach (L'Ascolto ${ }^{\circledR}$ ) on the educator's experiential learning process in a university accounting course. On one hand, the results show positive student performance, while, on the other, the positive effects of the educator's experiential learning emerge, as evidenced by the different teaching styles adopted during the course (flexibility).
\end{abstract}

Keywords: accounting education, deming cycle, experiential learning, higher education, Kolb, QFD, teaching methods

\section{Introduction}

The paper offers a reflection on the possibility of dealing with the complexity of teaching through a holistic approach that supports the educator's experiential learning development in his/her context. Holistic education means "[...] developing the whole person [...] education is not only cognitive knowledge of the facts, but also includes the development of social and emotional maturity" (Kolb, Kolb, Passeralli \& Shama, 2014). Thus, "learning flexibility indicates the development of a more holistic and sophisticated learning process" (Kolb et al., 2014). The educators' teaching style is influenced by the way they learn. Jung's theory holds that adult development passes from a specialized manner of adaptation toward a holistic integrated stage, thus the development of learning flexibility is seen as a transition from specialization to integration.

Adopting a flexible teaching style presumes that educators are aware of their learning styles and the need for flexibility in these styles. To develop learning flexibility in students, i.e. a more holistic, structured learning, the author proposes a holistic approach to the complexity of teaching (L'Ascolto ${ }^{\circledR}$, note 1). This approach will orient educators towards the Kolb Learning Cycle, thus envisaging a continuum of teaching processes in their relationship with students and their reference context. This can be considered as a sort of "training in flexibility".

There are many studies in the literature on student experiential learning in accounting (Butler, Church \& Spencer, 2019; Gitting, Taplin \& Kerr, 2020) although little attention has been given to the problem of the complexity of teaching. Less attention is paid to the educator's experiential learning using holistic approaches that consider this complexity.

Hence, the decision was made to observe and guide the experiential learning process of the educator of an accounting course attended by 215 second-year students of an Economics and Management degree course, using the experimental holistic approach, L'Ascolto. This approach applies the Deming cycle to design (Plan), management (Do), evaluation/self-evaluation (Check) and improvement/standardization of teaching processes (Act) encouraging the educator to go through the stages of the Kolb Learning Cycle (Concrete Experience - CE, Reflective Observation - RO, Abstract Conceptualization - AC, Active Experimentation - AE). The educator's 
continued reiteration of the PDCA cycle enables Experiencing (Do), reflecting (Check), thinking (Act) and acting (Plan/Do), to understand of his/her experiences (Do/Act) and allows the educator to transform them (Check/Plan) by adapting his/her own behaviour (learning flexibility).

Educators do not always receive adequate training to enable them to recognise their learning and teaching styles thereby hampering their development of flexibility when both learning and teaching.

The work aims firstly to verify if the holistic approach of L'Ascolto can help educators to progress through the Kolb Learning Cycle while respecting the complexity of teaching, namely in a continuum of learning processes involving both their relationship with students and their reference context. In addition, it aims to check whether this "training" in flexibility also produces flexibility in the educator's teaching styles and, finally, whether this has a positive impact on student performance. However, it should be noted that the work does not focus on demonstrating evidence of student performance (although this is presented at the end of the work) but is stimulated by the desire to identify "a process approach" that guide the educator through the Kolb experiential learning process in his/her specific context. (of time, place and relationships).

Although measuring results is an important aspect "the problem in education is that instead of following theory, measurement often precedes it, with the result that we often find ourselves measuring something without knowing what it is" (Sternberg, 1997, p.108). Kolb et al. (2014) observe that "Yet the treatments in education are not uniform pills, but instruction carried out by unique educators in relationship with equally unique students, influenced by a wide variety of contexts" (p.211).

The work is divided into three parts. The analysis of the literature anticipates the presentation of the L'Ascolto experimental holistic approach related to the Kolb Learning Cycle. There then follows an analysis of the experimentation phases of the "Deming/Kolb" approach in an accounting course and the results achieved.

\section{Literature Review}

\subsection{Complexity, Holistic Approach and Experiential Learning}

\subsubsection{Complexity}

It is noted that holistic education requires an analysis of complexity, of the general/entirety and not only of the individual parts. Concerning the concept of complexity, Morin (2001) observes how complexus refers to elements woven together: there is complexity when the different elements that make up the whole are inseparable. Ultimately, there is a close interdependence between the object of knowledge and its context, between the parts and the whole (and vice versa) and between the parts themselves (p.38). In his writings on the university, Newman (1999) also links them back to a single whole. Complexity is the link between unity and multiplicity. In today's world we are forced to face the challenges of complexity, "consequently education must promote 'general intelligence' capable of referring to what is complex, to the context in a multidimensional way and to the global" (Morin, 2001, p. 38).

Higher education must necessarily address complexity, as teaching is by its nature complex and this can be neither ignored nor avoided. The concept of didactic complexity (Casey, Gentile, \& Bigger, 1997) is linked to aspects concerning the time in which learning takes place (dynamic aspect) (Olwia, 1996; Marsh \& Roche, 1997), the variables involved and the links between them (systemic aspect) and the social, disciplinary and cultural context of reference (Lawn, 1991; Carpenter \& Tait, 2001). If, therefore, the objective is to improve student performance, this can only occur through the development of the educator's professional skills within his/her context (systemic aspect) and on an ongoing basis as regards the provision of learning processes (dynamic aspect) and regarding the individual's context (discipline, university, culture, etc.). It is, therefore, necessary to tackle the complex nature of teaching with a holistic approach that takes all these aspects into consideration. The literature on student performance assessment in accounting courses is highly developed, yet little attention is paid to the evaluation of students' performance related to an assessment of the educator's performance (systemic aspect) throughout the delivery of the course (dynamic aspect) and related to the needs of the context (discipline, University, stakeholders, etc.). Hence, it is necessary to reflect on the possibility of evaluating student performance through holistic approaches (Verna, Ianni, D'Andreamatteo, \& Venditti, in press).

\subsubsection{Holistic Approach}

L'Ascolto is a holistic approach aimed at the continuous improvement of all university teaching and education processes by listening to, and satisfying, the needs of all those involved in education, teaching and training in a systemic, dynamic and contextual way (Verna, 2017; Verna, Antonucci, Sargiacomo, \& Venditti, 2019).

It can be noted that in accounting there is a lack of studies that address the issue of improving student 
performance through holistic approaches. That is, approaches that consider listening and the satisfaction of educational actors (students, teachers, institutional bodies, social partners) in a systemic, dynamic and contextual way.

In the literature, there is a recognized need for a holistic approach to higher education (Sakthivel \& Raju, 2006) and numerous studies address these issues (Horine \& Hailey, 1995; Burkhalter, 1996; Barnard, 1999). However, the need to address the wider management context of the institutions has emerged that goes beyond a "partial holistic" (Mantos, Sarrico, \& Rosa, 2017).

When we accept complexity, we aim to achieve the overall cognitive development of both the educator and the students in the teaching processes underway and in the context in which the teaching takes place. Therefore, if it is desirable to educate the student holistically, it is essential that this (social and emotional) maturity is present in the educator and that it constantly evolves.

It has already been noted how "Learning flexibility indicates the development of a more holistic and sophisticated learning process (Kolb et al., 2014). Sternberg points out that "[ [...] the advantages of flexibility are so overwhelming that one wonders why we do not emphasize it more in teaching our children, students, and employees" (p.105). An attempt was made to combine the quest for flexibility in the educator's learning styles with a holistic approach to university teaching to tackle the complexity of teaching.

\subsubsection{Experiential Learning}

In recent years, there has been great development in student-centred experiential education (Bielefeldt, Dewoolkar, Caves, Berdanier \& Paterson, 2011). Kolb's Experiential Learning Theory (ELT), has been disseminated widely by experiential educators in numerous fields and academic disciplines (Kolb \& Kolb, 2013). There are numerous studies on student-centred learning environments in accounting too (Canboy, Montalvo, Buganza \& Emmerling, 2016; O'Connell, Carnegie, Carter, de Lange, Hanchock, Helliar \& Watty, 2015). In the realm of Experiential Learning Theory - ELT, these studies highlight, for example, the benefits of good Experiential Learning Activities - ELA (Butler, Church \& Spencer, 2019; Gitting, Taplin \& Kerr, 2020). However, it has been observed that the pedagogical benefits deriving from the implementation of experiential education in accounting courses are accompanied by challenges that need to be addressed (Butler, et al., 2019, p.16). Specifically, "instructors implementing an experiential learning model must adequately prepare for an uncontrolled environment to effectively manage the experience and to mitigate low student satisfaction. [...] research, training, planning, and communication by instructors can alleviate the potential risks of these challenges of implementing experiential education" (Butler, et al., 2019, p.17).

Ultimately, the educator's training cannot be taken for granted or detached from that of the student. This once again brings us back to the issue of complexity, or the systemic aspect of the relationship between the parties (educators, students) and the dynamic aspect linked to the time in which this relationship takes place. Thus, the paper attempts to contribute to the literature by focusing on the educator's experiential development guided by a holistic approach (for the observation and understanding of complexity). The aim is to develop flexibility in students' learning styles through the development of flexibility in the educator's learning and teaching styles. The work is therefore based on Kolb's experiential learning (1984) and on the theoretical support that precedes it.

In particular, Kolb's experiential learning concept, which derives from Vygotsky's concept of the Proximal Development Zone, is based on the assumption that learning is the result of an interaction between what we experience in a specific context and the knowledge present in an individual at a given moment. Kolb shared and collected the prominent works of important twentieth-century scholars such as John Dewey, Kurt Lewin, Jean Piaget, Vygotsky, William James, Carl Jung, Paulo Freire, Carl Rogers and Follett who developed a dynamic and holistic model of the process of learning from experience and a multilinear model of adult development (Kolb et al., 2014). As noted by the author, individuals build their knowledge within their environment, and experiences can be transformed into learning. Thus, learning is the result of a reflection on action. Knowledge is the result of either the observation of concrete experiences or the understanding of abstract conceptualizations, transformed by reflective observation and expanded by experiment. Kolb's experiential learning cycle is, therefore, developed as a dynamic vision of learning "driven by the resolution of the dual dialectics of action/reflection and experience/abstraction" (Kolb et al., 2014, p.213). Quoting James, Kolb highlights how everything starts and ends in the continuous flow of experience (James, 1912, p.4). The continuous exposure to experience in an endless cycle allows gradual, continuous improvements in the logic of experiential learning. Kolb et al. (2014) define learning as "...the process whereby knowledge is created through the transformation of experience. Knowledge results from the combination of grasping and transforming experience" (Kolb, 1984, p.41). The scholar underlines how "grasping experience refers to the process of taking in information, and transforming 
experience is how individuals interpret and act on that information".

Specifically, the two scholars (Kolb et al., 2014) highlight how learning must be considered in terms of process (and not result): a holistic process of adaptation to the world that arises from the synergy between people and their environment, a process of knowledge creation.

Therefore, to develop holistic education we require an approach to teaching that respects its complexity (systemic, dynamic and contextual) while recognising that it is a process that creates knowledge through the observation and transformation of experience. To this end, L'Ascolto applies the Deming cycle (PDCA) to the teaching processes, directing the educator's experiences towards continuous cycles of lesson design for the course (Plan), management of teaching processes (Do), evaluation/self-evaluation of learning outcomes (LO) (Check) and improvement of training processes (Act). The educator then learns dynamically through concrete experiences (Do), transformed by reflective observation (Check) and expanded by abstract conceptualization (Act) and active experimentation (Plan). In this sense, in a structured and systematic way, L'Ascolto fuels a system that creates, manages and shares the knowledge deriving from these processes. The educator, therefore, learns through continuous exposure to experience in an endless cycle (Deming/Kolb) that allows gradual but continuous improvements within the logic of experiential learning. By encouraging the educator's experiential learning in the different phases of design, management, evaluation and improvement, L'Ascolto enables the educator to pass through the stages of experience, reflection, abstract conceptualization and active experimentation, in order to improve gradually but continuously. As already noted, the aim of this work is to verify whether it is possible to induce "flexibility training" in the educator's learning styles and then to verify if this reflects on teaching styles (flexibility) and student performance. To this end, the following paragraph presents a reflection on the evidence in the literature regarding flexibility. We then further analyse the Kolb Learning Cycle and its possible application to the L'Ascolto holistic approach.

\subsection{Flexibility in Teaching and Learning Styles}

Learning style can be defined as "[...] a description of the attitudes and behaviour which determine an individual's preferred way of learning" (Honey \& Mumford, 1992, p.1). Hayes and Allison (1996) note how "learning style is a potent individual characteristic that may have important consequences for the efficiency and effectiveness of training and development" (p.71). When discussing learning styles, "Scott, citing Dweck (2008), argues that this is an entity approach to ability that promotes stereotyping and labelling rather than a process approach that emphasizes developmental potential and contextual adaptation" (Kolb et al., 2014).

The literature investigating students' learning styles is particularly vast. It has been found that specific student learning styles are associated with better performances (Riding \& Douglas 1993). Hence, different approaches have been proposed with the aim of creating conditions that may improve student performance. Examples of such studies are those of Witkin (1976), Kolb (1984), Honey and Mumford (1992), Rush and Moore (1991). Numerous empirical studies evaluate the impact of alignment or misalignment of these styles on student performance (Mcdonald, 1984; Rush \& Moore, 1991; Duff, 1998; Visser, McChlery, \&Vreken., 2006). Students' learning styles may be compatible or incompatible with the educator's teaching styles. There are many advocates of a correspondence between teaching and learning styles (Haddon \& Lytton, 1968; Felder, 1993; Ford \& Chen, 2001; Visser et al., 2006). Some authors highlight how, for example, "students whose learning styles are compatible with the teaching style of a course instructor tend to retain information longer, apply it more effectively, and have more positive post-course attitudes toward the subject than do their counterparts who experience learning/teaching style mismatches" (Felder, 1993). By contrast, other scholars do not detect such evidence (Messick, 1976; Kogan, 1980; Miller, 1991), leading to ambiguous results (Zhang, 2006).

There are numerous studies in the literature that underline the advantages deriving from compatibility between the teaching styles of the educator and the student's learning (Felder, 1993) and their effects on student performance. In particular, some studies (Kolb, 1976; Honey \& Mumford, 1986) propose to overcome weaknesses in students' learning styles with teaching styles that do not correspond to students' natural learning preferences, thus developing a more integrated and flexible approach to learning. Emeritus scholars including Sternberg, Kolb and McIntry have strongly emphasized how the educator's flexibility in teaching styles has extremely positive effects on the students' learning outcomes compared to teaching based on a single style.

Thus, the educator's flexibility in teaching styles can meet the different learning styles of students and work on the flexibility (Kowoser \& Berman, 1996) that students need to acquire in their cognitive styles to respond to the varied requirements of the environment (Honey \& Mumford, 1986). In this regard, Rush and Moore (1991) observe how by stimulating students to learn in a form that does not correspond to their preferred style may enable them to overcome weaknesses in their cognitive styles and thus improve learning. This presumes that the 
educator is aware of his/her learning and teaching styles. Without this awareness, it is difficult to imagine how there might be an influence on students' learning outcomes, unless by chance. Hayes and Allinson (1996), therefore, highlight the need for further research aimed at exploring how educators may be helped to become more flexible in their teaching styles. This paper attempts to contribute to such research. Note that educators often fail to receive the necessary training to achieve knowledge and mastery of their own styles and hence cannot provide flexibility. For example, if educators were able to work on their learning style, to "train" in being flexible, this could, in turn, make their teaching styles more flexible and thus influence their students' learning styles. The following paragraph provides a brief outline of Kolb's experiential learning process to highlight if and how the L'Ascolto approach supports the development of the experiential learning of the educator in his/her context.

\subsection{Kolb Experiential Learning Cycle}

Kolb proposed a model of learning styles that explains the process that underlies learning, namely, a process that creates knowledge through the observation and transformation of experience (Kolb, Rubin, \& McIntyre, 1971). The authors describe knowledge as a transformation of experience through a never-ending 4-stage cycle (Concrete Experience - CE, Reflective Observation -RO, Abstract Conceptualization -AC, Active Experimentation -AE). The learner can enter the cycle at any of the stages provided in the model, as each is linked to another. For example, in the Concrete Experience the person performing the action observes the effect of that action thus fuelling the next stage (Reflective Observation). The interpretation of events leads to abstract generalizable concepts (Abstract Conceptualization) to be experimented in new situations (Active Experimentation). The process is repeated with the new information that comes from Concrete Experience and so on in a continuous loop. A dynamic vision of learning is created that is guided by "[...] two dialectically related modes of grasping experience - Concrete Experience (CE) and Abstract Conceptualization (AC) - and two dialectically related modes of transforming experience - Reflective Observation (RO) and Active Experimentation (AE)" (Kolb et al., 2014, p.214). The important aspect is to go through all the stages to achieve gradual and continuous improvements towards balanced learning. Passing through these stages means understanding your experiences and changing your behaviour. Ultimately, when learning takes place, the process appears as a spiral where the person learning in different circumstances can anticipate the possible effects of an action. Effective learning is, therefore, represented by possessing skills derived from Concrete Experience, Abstract Conceptualization, Reflective Observation, Active Experimentation (Kolb \& Fry, 1975). Figure 1 shows the whole cycle.

The problem is that frequently people only address one or more of these stages with the correct skills, thus not all the stages produce the same results, and some stages may not be addressed at all. Different styles are defined according to the preferred stages in the learning path: Diverging, Assimilating. Converging and Accommodating. The choice between the different learning modes depends on one's genetic makeup, specific life experiences, and the demands of the present environment; thus, a preferred choice among these four learning modes develops (Kolb et al., 2014).

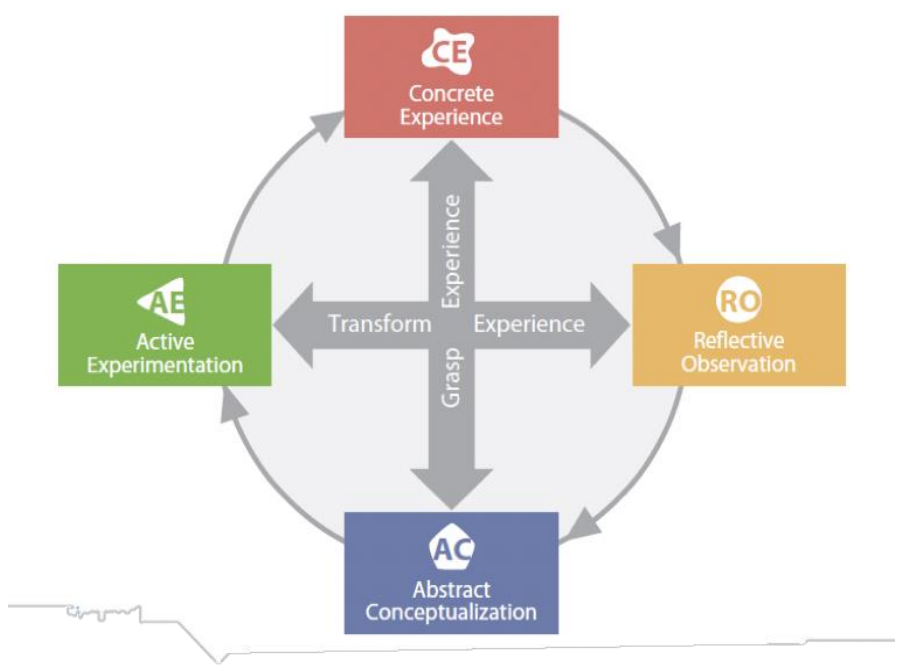

Figure 1. The Experiential Learning Cycle (Kolb \& Kolb, 2013) 
Two fundamental but independent aspects emerge from Kolb's theory (Duff, 1998, p.337): the experiential learning process in which the four previously described stages take place, and two orthogonal bipolar dimensions created from opposite pairings of the four stages: action/reflection and experience/abstraction (Kolb \& Kolb, 2013, p.7). In the first case, individual differences are explained in terms of skills in each stage, while they are defined in terms of learning styles in the second case. "Learning style is not a fixed personality trait, but more like a habit of learning shaped by experience and choices - it can be an automatic, unconscious mode of adapting or it can be consciously modified and changed" (Kolb et al., 2014). Kolb developed a theory of experiential learning (ELT) that gave rise to the Learning Styles Inventory, LSI (Kolb et al., 1971; Kolb, 1976) and subsequent versions (Kolb, 1985; Kolb, 1999; Kolb \& Kolb, 2013).

There now follows a brief description of the different learning modes that are explained in much greater detail by the above-cited authors. Learners with a diverging style have a preference for concrete experience and reflective observation while those with an assimilating style prefer abstract conceptualization and reflective observation. On the other hand, learners with a converging style prefer abstract conceptualization and active experimentation and finally, people with an accommodating style prefer concrete experience and abstract conceptualization. The learning style questionnaire was used by Kolb and Fry (1975) to highlight that there are strengths and weaknesses associated with each style and underline how important it is to overcome one's weaknesses by moving beyond any style that is too deeply rooted: "learning flexibility is the ability to use each of the four learning modes to move freely around the learning cycle and to modify one's approach to learning based on the learning situation. Experiencing, reflecting, thinking, and acting each provide valuable perspectives on the learning task in a way that deepens and enriches knowledge" (Kolb et al., 2014, p.218).

These considerations allow us to reflect on the possibility of "aiding" the educator to go through the Kolb experiential cycle by using a holistic approach to university teaching aimed specifically at developing flexibility in the learning and teaching styles of the educator within his/her context. In the following paragraph, we will examine this possibility.

\subsection{Holistic Approach to Higher Education and Experiential Learning: "Deming Towards Kolb"}

Considering both the complexity of teaching alongside the possibility of developing flexibility in the educator's learning styles for a more integrated, holistic learning process, this part of the paper proposes an experimental holistic approach: L'Ascolto (Verna, 2017; Verna et al., 2019). This approach aims to tackle the complexity of teaching by listening to and satisfying the needs of the actors involved in the education process, in a systemic, dynamic and contextual way. Hence, L'Ascolto applies two Total Quality methodologies (Feingembaum, 1956; Juran, 1962; Deming, 1951), that is, Quality Function Deployment, QFD (Akao, 1990) and Deming's (1951) PDCA cycle (Plan, Do, Check, Act) for the design (Plan), management (Do), evaluation/self-evaluation (Check) and improvement of teaching processes (Course of studies and single course units) considered as a single whole. This work proposes the application of L'Ascolto to a single unit of an accounting course (in a Degree Course in Economics and Management) to more clearly highlight the contribution that L'Ascolto makes to the educator's experiential development in this specific teaching/learning environment. While attention is thus focused on the learning needs of educators and students, the approach of L'Ascolto listens to and meets the needs of all the actors in education, training and learning (Verna, 2017; Verna et al., 2019). The educators' continued reiteration of the PDCA cycle, Experiencing (Do), reflecting (Check), thinking (Act) and acting (Plan/Do), enables them to understand their experiences (Do/Act) and to transform them (Check/Plan) by adapting their behaviour (learning flexibility). L'Ascolto thus offers the educator a dynamic vision of learning, guided by that double dialectic (of understanding the experience) of grasping experience (Concrete Experience - CE and Abstract Conceptualization -AC) and transforming experience (Reflective Observation - RO and Active Experimentation - AE). In particular it was observed that: "Learning arises from the resolution of creative tension among these four learning modes" (Kolb et al., 2014, p.214). Figure 2 offers an overall view of the "Deming/Kolb cycle", emphasizing the two-fold dialectic of grasping experience and transforming experience in the specific context of needs, systemic relationships and dynamic evolutions in which learning is created, through gradual and continuous improvements. It should be noted that the specific context refers to the systemic and dynamic relationship between the needs of the actors involved in the teaching process expressed synthetically as: target, needs and learning outcomes. The course targets (note 2) relate to the students' initial needs (entrance test), i.e. the gap between the students' ideal educational level (target) and the level of the students at the outset of the course (results of the entrance test). Listening to students' needs is repeated at the end of each course module (dynamic approach), thus highlighting any gap between students' learning during the course (LO) and the ideal level. The needs relate to those of the educators during the course as expressed by the gap between the ongoing learning of the students (learning outcomes) and the targets. Hence, the educator's learning needs relate to the gap between the educator's initial 
level of training and that required to meet the students' needs (systemic approach). The relationship between the targets, needs and learning outcomes is, thus, the specific context of learning needs in which the steps of the PDCA cycle, briefly reported below, take place. It should be noted that the educator does not acquire generic knowledge devoid of context, but knowledge linked specifically to the context of place, time and relationship in which he/she acts. In this regard, Lave and Wenger (1991) affirm that learning must not be stripped of its context, but set in the environment and in the person's life path (Kolb, 2014).

The stages of the experiential learning cycle that the educator is encouraged to follow are illustrated for each stage of PDCA.

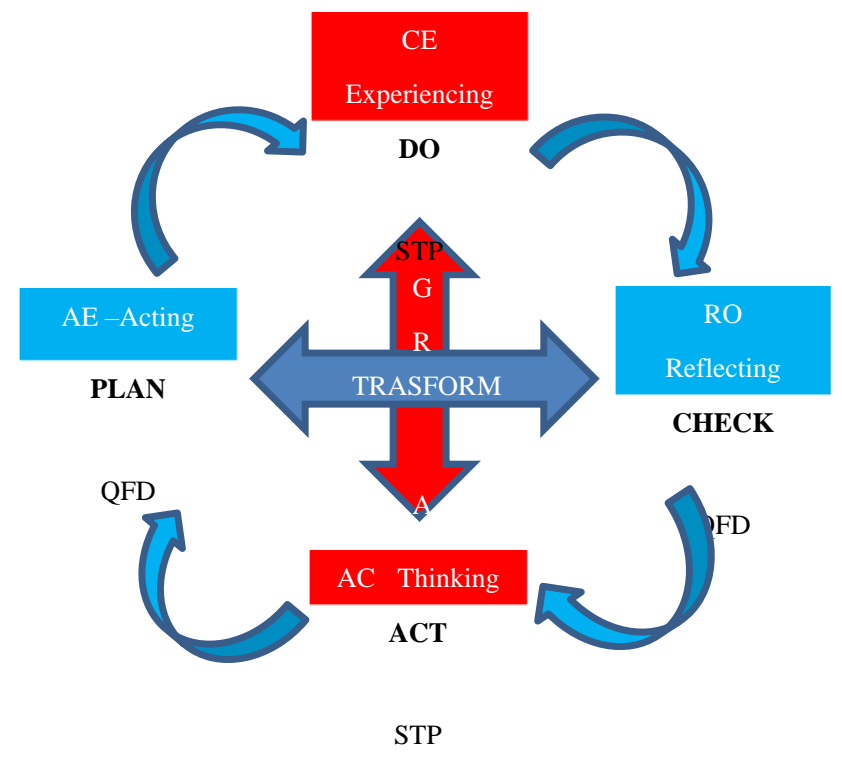

Figure 2. "Deming/Kolb cycle"

\subsubsection{The Plan Stage}

In the course design stage (Plan), carried out using QFD, Figure 3 (Verna, 2014), the educator defines the objectives of the course modules (and of the single lessons), in line with those defined in the planning of the course of studies (stakeholders' needs) and listening to the needs of the learners (entrance test) columns one and two. The students' needs are expressed in terms of homogeneity (upwards or downwards) or heterogeneity in the level of knowledge expressed by the class of incoming students (initial needs) with respect to the various course objectives. Based on the specific context of the needs, the educator identifies the most appropriate didactic strategies to satisfy these needs. The teaching strategies (figure 3) combine the different methods, tools and times selected by the educator for the pursuit of specific objectives (Verna, 2014).

\subsubsection{The Do stage}

The design stage of the course (Plan) is followed by the management stage of the teaching processes, (Do). The Do stage permits the educator to implement what has been planned to the different modules of the course. At the end of said stages (Plan, Do - experiencing) the educator will move on to the Check stage of reflection on the recently completed experience (reflecting).

\subsubsection{The Check Stage}

In this stage, the educator listens to the students' "learning needs" using quantitative and qualitative tools. Specifically, the Check stage enables the educator to reflect on the learning level achieved by the class of students with respect to the targets of the module just completed (LO) as well as reflecting on their own "learning needs". It should be noted that listening to the "learning needs" of educators, as against that of students, is implemented through the evaluation/self-assessment tools that monitor the key processes of teaching quality in a specific context (Verna, 2017; Verna et al., 2019).

The literature refers to the concept of teaching quality building blocks (Probst, Raub, \& Romhardt, 2002; Ramsden, 2003) that some authors have organized (Chen, Chen, \& Chen, 2014) into ten constellations. In L'Ascolto, the 
"key processes" concern the design, management, evaluation and improvement of the teaching quality, while within the management phase (DO) some teaching quality "control areas" are monitored, namely, disciplinary skills, teaching strategies, communication and relational techniques. It should be noted that the "control areas" can be extended according to the educator's professional development in his/her specific context (Verna, 2017; Verna et al., 2019). In the Check stage, for example, at the end of the first course module, the educator gives the students a test to assess to what extent the targets of the completed module have been achieved. In addition to the end-of-module test, at the end of the first, intermediate and final module, the educator gives the students a course satisfaction questionnaire that focuses on the "control areas" of teaching quality mentioned above. If the results of the test (students' LO) are unsatisfactory, the educator fills in a self-evaluation questionnaire, mirroring the satisfaction questionnaire given to the students.

\begin{tabular}{|l|l|}
\hline \multicolumn{2}{|c|}{ Relationships: } \\
\hline $5-$ Strong relationship & + \\
\hline $3-$ Medium relationship & - \\
\hline $1-$ Weak relationship & $\mathrm{X}$ \\
\hline
\end{tabular}

\begin{tabular}{|c|c|c|c|c|c|}
\hline \multirow{2}{*}{\multicolumn{2}{|c|}{$\begin{array}{ll}\text { Educational } \\
\text { strategies }\end{array}$}} & \multirow[b]{2}{*}{ Needs } & \multirow{2}{*}{$\begin{array}{c}\text { Strategy } \\
\quad 1 \\
\text { class/ } \\
\text { tutorial }\end{array}$} & \multirow{2}{*}{$\begin{array}{c}\text { Strategy } 7 \\
\text { Role- playing/ } \\
\text { tutorial/ } \\
\text { class }\end{array}$} & \multirow{2}{*}{$\begin{array}{c}\text { Strategy } 3 \\
\begin{array}{c}\text { Study Case } / \\
\text { class }\end{array}\end{array}$} \\
\hline & & & & & \\
\hline \multirow{10}{*}{ 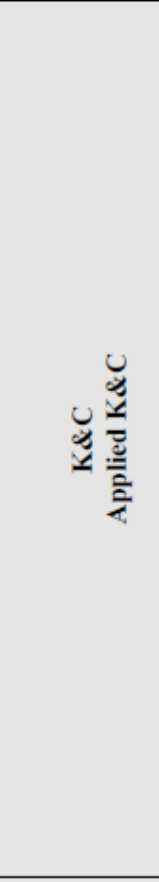 } & $\begin{array}{l}\text { 1. General accounting } \\
\text { (objectives tools e methods) } \\
\text { BASIC }\end{array}$ & 9 & + & - & \\
\hline & ADVANCED & 9 & + & - & \\
\hline & $\begin{array}{l}\text { 2. National and International } \\
\text { accounting principles } \\
\text { (conceptual framework, classification } \\
\text { and analysis) } \\
\text { BASIC }\end{array}$ & 10 & + & + & \\
\hline & ADVANCED & 10 & + & + & \\
\hline & $\begin{array}{l}\text { 4. Capital } \\
\text { (definition, composition) } \\
\text { BASIC }\end{array}$ & 8 & + & + & \\
\hline & $\begin{array}{l}\text { (configuration/determination) } \\
\text { ADVANCED }\end{array}$ & 9 & + & + & \\
\hline & $\begin{array}{l}\text { 4. Income } \\
\text { (definitions, composition) } \\
\text { BASIC }\end{array}$ & 9 & + & + & \\
\hline & $\begin{array}{l}\text { Configuration, } \\
\text { determination } \\
\text { ADVANCED } \\
\end{array}$ & 10 & + & + & \\
\hline & $\begin{array}{l}\text { 5. Budget } \\
\text { (notions, discipline, } \\
\text { characteristics) } \\
\text { BASIC }\end{array}$ & 10 & + & + & \\
\hline & ADVANCED & 10 & + & + & \\
\hline \multirow{4}{*}{ 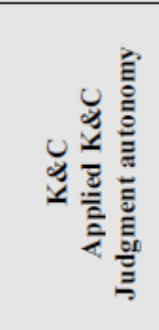 } & $\begin{array}{l}\text { 3. Recognition of the main } \\
\text { management operations } \\
\text { (domestic and international markets) } \\
\text { BASIC }\end{array}$ & 9 & + & + & $\mathrm{x}$ \\
\hline & ADVANCED & 10 & + & - & - \\
\hline & $\begin{array}{l}\text { 6. Balance sheet } \\
\text { (composition., determination) } \\
\text { BASIC }\end{array}$ & 10 & + & + & + \\
\hline & ADVANCED & 10 & - & - & + \\
\hline \multicolumn{3}{|c|}{ Weights of educational strategies } & 645 & 589 & 139 \\
\hline
\end{tabular}

Figure 3. Initial QFD (adapted from Verna, 2014) 
The comparison between the teacher's self-evaluation test and the student satisfaction test allows the teacher to listen to his/her own "learning needs", that is, to identify the "control areas" which require action to satisfy all the needs. Kolb (1984, p.41) considers learning as a mental process oriented towards a goal that requires conscious reflection. As already noted, learning is considered as a process of continuous construction and reconstruction, which occurs through the interaction of the individual's knowledge with the knowledge of the environment. Thus, the learning style is not a fixed psychological or cognitive trait, but rather the result of the interaction between the person and environment (Kolb \& Kolb, 2013). Therefore, in this Check stage, the educator is prompted to reflect on the recently concluded teaching processes for one purpose: to bridge the gap between his/her initial training (before the start of the course) and that required to meet the students' "learning needs". The educator pursues this aim through continuous interaction with the environment in which he/she works (specific context).

Specifically, the educator can reflect on the recent experience in terms of:

- (Level of) satisfaction of students' "learning needs" (entrance test, end-of-module test, end- of-course test);

- (Level of) satisfaction of educators' learning needs (student satisfaction test/educator's self-evaluation);

- Teaching gap to be filled (the educator's reflection on the control areas on which action must be taken self-training)

The Check stage, therefore, offers the educator the opportunity to reflect on the experiences achieved thanks to a plurality of systemic, dynamic and contextual information sources, that fuel the next stage, Act (thinking).

\subsubsection{The Act Stage}

This is the stage in which the educator develops teaching strategies to reduce the gap between students' actual learning (LO) and the ideal level (target). As noted by Coleman (1976), generalizing (abstract conceptualization) involves the ability to see a connection between actions and effects in a range of circumstances. In this sense, this stage provides the educator with the opportunity to formulate teaching strategies aimed at bridging the students' learning gap through the development of new knowledge. Hence, the teacher develops new strategies in terms of:

- solutions to problems that emerged in the "control areas" (disciplinary skills, teaching methodologies and communication and relational techniques);

- comparison with colleagues (best practices of educators who have worked in the same environment target/needs/LO).

In the Act stage, the educator formulates his/her teaching strategies based on the information collected in the previous stage, to then experiment them in the Plan (Acting) phase. The cycle is repeated in the next module in which the educator experiments the formulated strategy and verifies its effectiveness (Check). When the outcome is positive, the educator has no need to formulate new teaching strategies, but having reached the Act (thinking) stage, she/he standardizes the strategies that proved successful by answering the questions present in the Standardization Forms for Teaching Professionalism (STP). The best practices of educators who have improved achievement to fulfil the LO in a specific context are standardized in these sheets. The STP consists of two sheets. The first sheet contains the teaching strategies that enabled the educator to achieve higher LO (i.e. 98\% homogeneity of the class of students during the course or at the end) compared to specific targets and the relative initial needs of the students (Verna, 2017; Verna et al., 2019). The second sheet standardizes the choices related to the discipline and the communication and relational techniques that permitted the educator to achieve the results in that context (LO/targets/initial needs), Figures 4 and 5. Educators who find themselves working in the same conditions, can thus draw on a knowledge management and sharing system - STP - that allows comparison between peers (best practices). It should also be noted that the STPs represent the synthesis of a system of creation, management, sharing and conservation of knowledge deriving from a continuous process of design, management, evaluation and improvement of the quality of university teaching, guided by listening to and satisfying the needs of educators and students. In L'Ascolto, the satisfaction of the educator's needs is achieved when, in specific circumstances of target, initial needs and learning outcomes, the educator either evaluates the gap between the learning outcomes of students and the targets as the students progress, thus identifying the "control areas" on which action must be taken to reduce or remove this gap or, alternatively, chooses the best practices of another educator who has operated with success under the same conditions and in the same context" (Verna et al., 2019). 


\begin{tabular}{|c|c|c|c|c|}
\hline Target & & $\begin{array}{c}\text { STP 1 } \\
\text { Teaching Strategies }\end{array}$ & Needs & L.O. \\
\hline 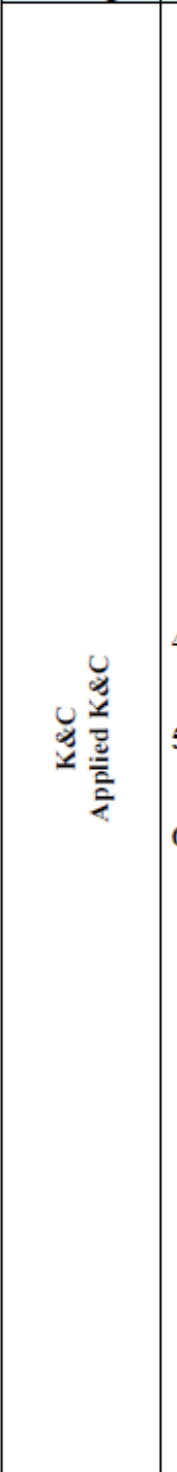 & 6 & $\begin{array}{l}\text { 4. Where is the class held? } \\
\text { Did you change class during the lesson or used a particular place (e.g. computer } \\
\text { room, company visit)? } \\
\text { Item } 4 \text { : adopts different methods so that individual work is alternated with that of } \\
\text { group and pair work (score 1). } \\
\text { Brief description of the chosen solution: } \\
\text { The game created by the educator is an adaptation of tic-tac-toe for the } \\
\text { reinforcement and summarizing of the course's basic contents (target of the last } \\
\text { module of the course). The procedure was to divide the class into two teams and } \\
\text { within each team the members worked in pairs. The answers to all the questions are } \\
\text { finally summarized to the whole class by the educator and in a summary document } \\
\text { (handout). The teacher leads the game by defining rules and times. The trio } \\
\text { represented on the blackboard contains a number in each box corresponding to a } \\
\text { question. The teacher chooses a student from both teams to hear the answer to the } \\
\text { question. }\end{array}$ & 10 & $\begin{array}{l}80 \% \\
90 \%\end{array}$ \\
\hline 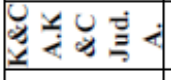 & & Strategy 1. Practical exercises / Lesson & 9 & $80 \%$ \\
\hline 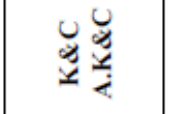 & 2 & $\begin{array}{c}\text { Strategy } 8 . \\
\ldots\end{array}$ & $\begin{array}{c}9 \\
10\end{array}$ & $\begin{array}{l}80 \% \\
85 \%\end{array}$ \\
\hline
\end{tabular}

Figure 4. STP 1 


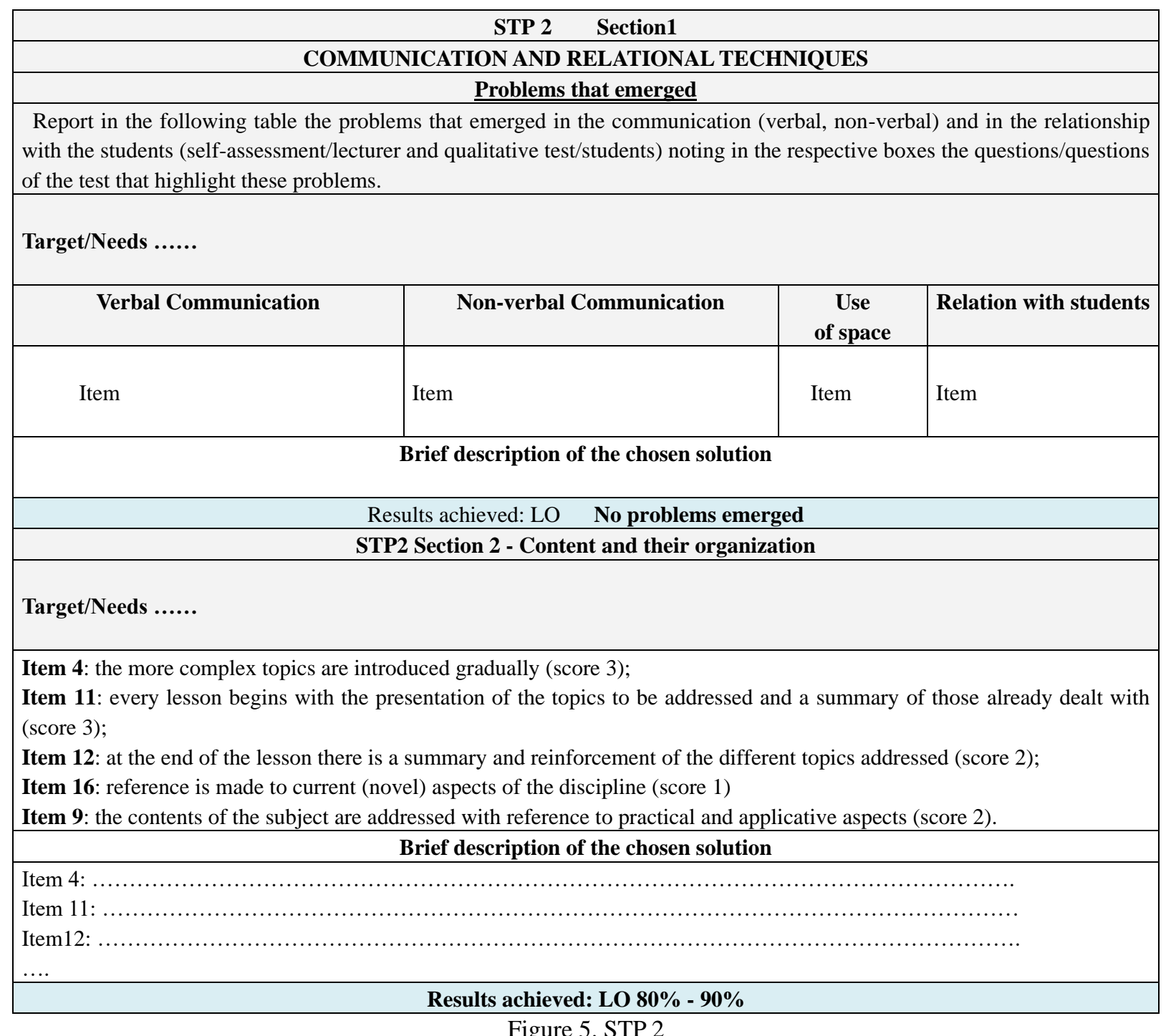

In this sense, Deming's Plan, Do, Check and Act cycle, with its continuous repetition over time, directs the educator towards continuous learning cycles through concrete experiences (DO), transformed by reflective observation (Check) and expanded by abstract conceptualization (Act) and active experimentation (Plan-Do). By following the "Deming/Kolb cycle", the educator can learn by resolving the "creative tension" between the stages of experiencing, reflecting, thinking, and acting. Thus, the assumption of experiential learning is that learning is built from the experience gained in a specific context, in interaction with the knowledge that an individual already has at that moment.

Figure 2 shows how in the Do (experiencing) and Act (thinking) stages, the educator tries to understand his/her personal experience and in the Check (reflecting) and Plan (Acting) stages, to transform it into knowledge. Note how the transformation of the experience is summarized in schematic form in the QFD in which the Plan (Acting) and Check (Reflecting) stages are highlighted, while the understanding of the experience is highlighted (as well as in the Do stage) in the STP. It should be noted that this form makes the result of the educator's experiential learning "visible", i.e. the creation of knowledge. Ultimately, it highlights the creation of knowledge that took place as a result of the educator's experiential learning in the Deming/Kolb cycle (albeit in a synthetic form and limited to the best practices of educators in specific context conditions). The continuous repetition of the PDCA cycles in a specific context gives the educator the opportunity to "resolve" the "creative tension" between the stages of experiencing, reflecting, thinking and acting.

Hence, L'Ascolto fuels, in a structured and systematic way, a system that creates, manages and shares the knowledge deriving from the continuous exposure to experience in an endless cycle (Deming/Kolb) that allows 
gradual, continuous improvements in the logic of experiential learning. As noted earlier, learning flexibility is the ability to use each of the four learning modes to move freely around the learning cycle and to modify one's approach to learning based on the learning situation (Kolb et al., 2014, p.218). The following paragraph presents the results of the experimentation of the approach of L'Ascolto in a university accounting course to highlight the effects of this approach on flexibility in the teacher's learning and teaching styles and on students' performance.

\section{Method and Results}

\subsection{The "Deming/Kolb" Cycle in an Accounting Course}

As noted, several times, the purpose of the work is to verify whether the approach of L'Ascolto supports the educator's use of the Kolb Experiential Cycle to develop flexibility in his/her learning and teaching styles and to verify whether this flexibility has a positive effect on student performance.

To this end, the holistic approach of L'Ascolto was tested in a university accounting course in the second year of a 3 -year degree course in Economics and Management attended by 215 students, all of whom were involved in the experimentation.

The students' performances were evaluated by comparing the LO of the class of the students of the accounting course, both as they progressed and at the end of the course, with the knowledge possessed by the incoming students. The students were given an entrance test focused on the objectives of the course modules. As a whole, the class initially showed a poor knowledge of the discipline, or rather "downward homogeneity". As already noted, homogeneity/heterogeneity is determined by calculating the average of the marks and the standard deviation. This deviation allows you to determine the homogeneity (values close to the average) or heterogeneity of the level of knowledge possessed by the class of students. Students' needs are also listened to during the course, LO (dynamic aspect) as well as the related training needs of the educator (systemic aspect).

Before describing the methods of the experimentation, we recall that the PDCA stages of the "Deming/Kolb" cycle were presented in the previous paragraph, thus they will not be discussed in detail in this part of the paper. The reflection here focuses on the methods of experimentation and the results achieved. In particular, the two dialectically correlated modes of understanding experience and transformation of experience summarized respectively in the STP (initial and end-of-course, Fig. 4 and 5) and in the QFD (initial and end of course, Figures 3 and 6) are used to guide the understanding of these results. This schematic representation (figure 2) aims to highlight the listening to the "learning needs" (understanding of the experience) and the satisfaction of the same needs (transformation of the experience).

The educator started the experimentation from the Plan stage of the course design with the use of the QFD matrix, in which she divided the course into 6 modules (Fig. 3). The initial QFD highlights the Plan and Check phase in which the initial target/needs (of the students) and the teaching strategies that allowed the educator to satisfy these needs in previous years are reported (Verna, 2014; Verna \& Perozzi, 2014; Verna \& Pizzolitto, 2019). The final QFD (Fig 6) shows the Plan and Check stages reporting the students' target/needs and LO as the course progressed and the teaching strategies that allowed the educator to overcome unsatisfactory (high needs) LO.

The first and second columns of the initial QFD indicate the targets of the course modules and the relative initial needs of the students (entrance test) respectively, while the top row of the QFD matrix shows the teaching strategies (best practices) selected by the educator in the experimentations of previous years. In particular, the hierarchy presented in the QFD represents the standardization logic of the approach of L'Ascolto (Verna, 2017) according to which the teaching strategies (communication techniques and disciplinary skills) are organized, managed and shared in a systemic, dynamic and contextual way. It should be noted that these strategies are the result of the continuous improvement generated with the "Deming/Kolb" cycle in which the educator creates new knowledge based on the correlated (systemic) listening to the needs of teachers and students (and other stakeholders), repeated over time (dynamic) and with reference to the specific (target/needs/LO) and general (disciplinary, social, cultural) context. It should also be noted that in the experimentation of previous years not all the "control areas" of teaching quality envisaged in L'Ascolto were considered. However, in this work the experimentation was extended all the "control areas" (Verna, 2017, Verna et al., 2019). In the QFD, the targets of the course modules were classified according to the Dublin descriptors and divided into "basic" and "advanced" (Verna, 2014). The initial needs of students, as previously noted, are expressed in terms of the homogeneity (upwards or downwards) or heterogeneity shown by the class of students with respect to the course targets (Verna, 2014). These needs are also listened to during the course (dynamic aspect) and express the level of learning (LO) reached by the class of students (homogeneity/heterogeneity) at the end of each module (during the course). 
The needs are determined by calculating the mean and the standard deviation of the student entrance test (and those during the course - L.O.) and translating the results obtained to a scale from 0 to 10 . Thus, if the spread around the mean is great, the class is heterogeneous; on the other hand, if the values are all close to the mean the class is homogenous, (upwards - higher knowledge, or downwards - lower knowledge). This calculation is made for the class of students for every course target. The legend shows the symbols corresponding to values inserted in the centre of the QFD matrix by the educator, according to the stronger or weaker relationship between target/needs and teaching strategies. By multiplying the value present in the matrix for each need, we obtain the value that expresses the correlation, stronger or weaker, between the strategy and the target/needs (Verna, 2014).

The initial QFD (Fig. 3) shows how the class of students has a downward homogeneity (high "learning needs"). The most effective strategies identified by the educator in the QFD in relation to the needs expressed by the class of students, are strategies 1, 7 and 3. In relation to this initial situation, the educator implemented the PDCA cycle (in the manner seen above) and the students' LO are shown in the final QFD.

In particular, the educator implemented the lessons of the first module with the Do (experiencing) stage, after which, in the Check (reflecting) stage, she collected information (in the manner seen previously) on the students' LO, which, in this case, were only just satisfactory. In Fig.6, highlighting the LO column shows LO equal to 5.6 (in a range from 0 to 10) in correspondence with the target/needs of the first module. As noted, the lower the LO the lower the "learning needs" of the students. In the Act (thinking) stage, the educator modified strategy 1 by formulating a new strategy based on the information provided by the Check (reflecting) stage. Specifically, the student satisfaction questionnaire shows very low values for questions 4, 11 and 12 of the "control area" relating to disciplinary skills. The values attributed to each item can vary from 1 to 5 (Absolutely No - No - neither Yes nor No - Yes - Absolutely Yes).

The items in question are listed below:

- (Item 4) the more complex topics are introduced gradually (score 3);

- (Item 11) every lesson begins with the presentation of the topics to be addressed and a summary of those already dealt with (score 3);

- (Item12) at the end of the lesson there is a summary and reinforcement of the different topics addressed (score 2).

In the self-evaluation questionnaire, the educator had similar values for items 11 and 12 , while she had given a high value (score 5) for item 4.

This information allowed the educator to activate the Act (thinking) stage in which she decided to modify strategy 1 by introducing a new strategy, 8 (Fig. 6). In particular, in order to respond to the students' "learning needs" as expressed with items 11 and 12, the educator decided to integrate strategy 1 with a short closed-case focused on the topics to be addressed during the lessons. The case is used by the educator at the beginning of each lesson of the module as a presentation of the topics to be addressed and at the end of the lessons as a summary and reinforcement. Regarding item 4, the educator decided to reduce the topics related to the module's objectives, focusing instead on the fundamental aspects, to be gradually expanded and reinforced with the new strategy 8 . At this point, the educator experimented the strategy formulated (in the thinking stage) in the next Plan stage, starting a new "Deming/Kolb" cycle, which with the Do stage, offered the educator a new experience. The information deriving from the next Check phase shows very positive LO, i.e. very low values $(1,2)$ both concerning the reinforcement of the objectives of the previous module and the one just concluded (module 2 "National and international accounting principles/10"). In this case, in the Act (thinking) stage, the educator limited herself to standardizing strategy 8 in the STP (Figure 4 and 5), which will allow other colleagues in the same contextual conditions to consider this strategy. 


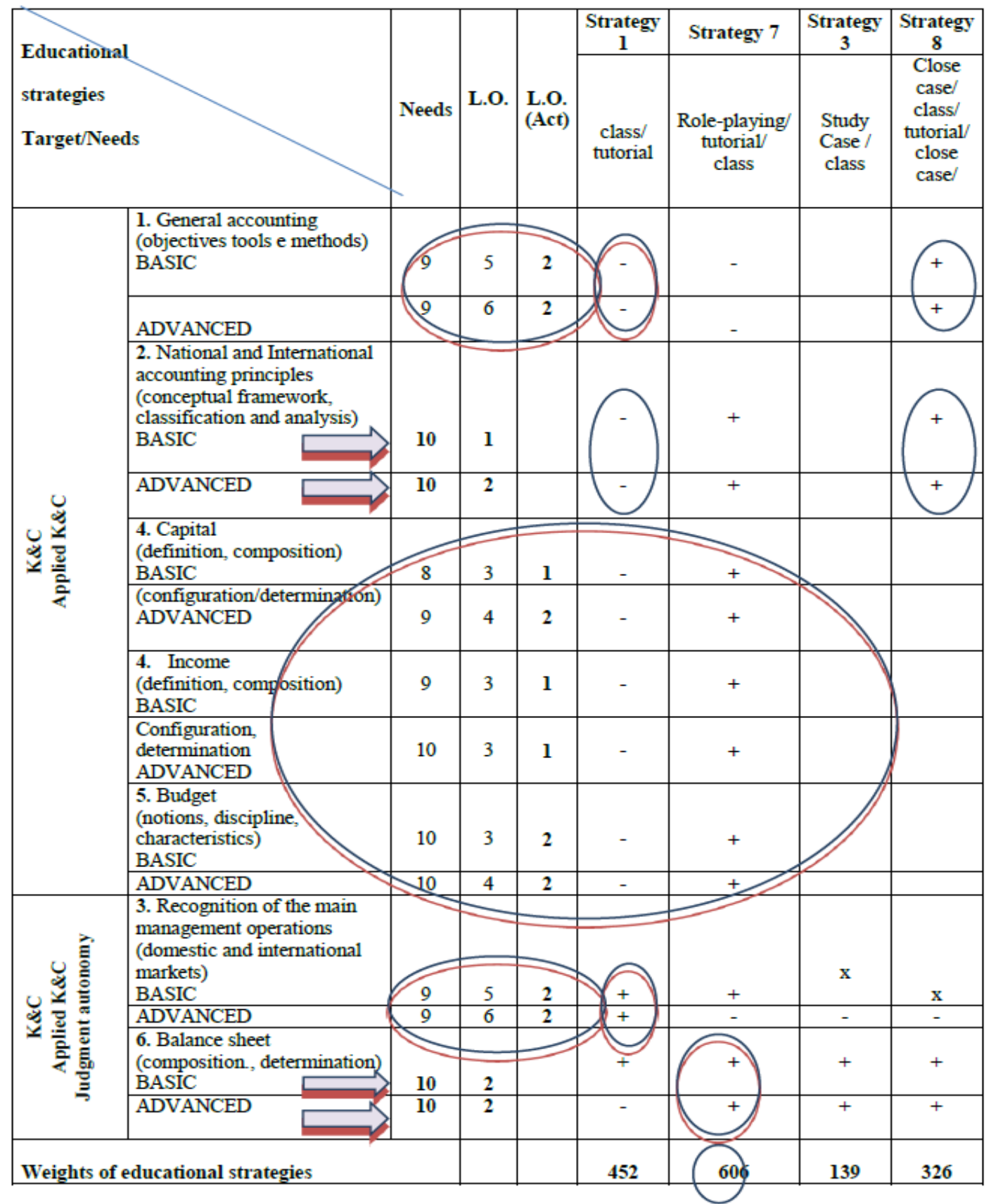

Figure 6. Final QFD

The cycle continued in the subsequent modules in the same manner, with module 3 highlighting unsatisfactory LO - 5 and 6 (with respect to the target/needs, "Recognition of the main management operations (domestic and international markets)/9").

The information provided by the Check stage of reflecting highlights some items of the student satisfaction questionnaire (again relating to disciplinary skills) that have modest values:

- (item 16) reference is made to current (novel) aspects of the discipline (score 1)

- (item 9) the contents of the subject are addressed with reference to practical and applicative aspects (score 2).

In this case, there were equally modest values in the educator's self-evaluation questionnaire.

In the Act (thinking) stage, the educator decided not to formulate a new strategy, but to use the practical application envisaged in the strategy to do exercises on sample cases taken from sector journals, integrated with handouts and further practical cases. 
The subsequent experimentation in the Plan and Do stages, allowed the educator to experiment strategy 1 in the experiencing stage (Do) and to evaluate the LO in the reflecting (Check) stage. In this case also, there were positive LO (very low values) that allowed the educator to standardize strategy 1 that was already present in the STP (Fig. 4 and 5). Standardization was limited to additions made by answering the questions required by the disciplinary skills standardization sheet. The aim is to allow continuous improvements in the formulation (thinking) of the proposed teaching strategies (teaching styles) for the benefit of all educators who work in the same contextual conditions. The teaching style can be considered as the combination of teaching methods and techniques preferred by an educator for conducting his/her lessons (Visser et al., 2006).

Ultimately, the strategies created by the educators (best practices) in the experiential learning process are accepted in the STP in a systematic way in order to allow the management and sharing of knowledge (teaching style) between educators who operate in the same context conditions. In this sense, L'Ascolto supports the educator in developing flexibility in teaching styles.

The results of the subsequent modules (4 and 5) were both positive ( 3 and 4 ) though not excellent, but the information offered by the Check stage allowed the educator to reflect on the possibility of further improving these results (filling the learning gap).

In particular, the last student satisfaction test (module 5) showed modest values compared to an item relating to teaching strategies:

- (item 4) adopts different methods so that individual work is alternated with that of group and pair work (score $1)$.

In the self-evaluation questionnaire, the educator had attributed a negative evaluation to the same item, justifying the choice with the number of students in the classroom (215). Considering the positive results shown by strategy 7 in the experiments conducted in previous years in the same context conditions and target/needs (Verna, Pizzolitto, 2019), the educator decided to adopt this strategy using an unusual activity: play. The game created by the educator is an adaptation of tic-tac-toe for the reinforcement and summarizing of the course's basic contents (target of the last module of the course). The procedure was to divide the class into two teams and within each team the members worked in pairs. The answers to all the questions are finally summarized to the whole class by the educator and in a summary document (handout).

The positive results of strategy 7, integrated by the game, are confirmed in the last module of the course both with respect to the reinforcement of the objectives of the previous module and the one just concluded, in which the students' LO are minimal (2).

As observed previously, the STP (Fig. 4 and 5) therefore highlights the result of listening to the experience (experiencing) and the elaboration of the educator's teaching strategies (thinking) or teaching styles (best practices) in a specific context (target /needs/LO). Considering the systemic and dynamic (holistic) approach on which L'Ascolto is based, this STP can show any flexibility in the educator's teaching styles (best practices) in terms of new formulations of teaching strategies (or the replacement of a strategy with another, or even additions to the strategy itself) in relation to the students' LO over time. Specifically, in the STP, the teaching strategies that have allowed the educator to achieve the most satisfactory LO (values close to zero) during the course are standardized in hierarchical order. The QFD matrix, on the other hand, offers a systemic and dynamic vision of the process of satisfying the initial and ongoing "learning needs" of students and teachers. As noted previously, the QFD shows a summary of the Check (reflecting) and Plan (Acting) stages of experience transformation that modifies behaviour, or that leads to flexibility in learning. This flexibility is the ability to use each of the four learning modes to move freely along this learning cycle, modifying one's behaviour according to the learning situation (Kolb, 2014).

\section{Conclusions and Discussion}

The research questions the paper proposed can be answered in the following considerations. The experimentation stage made it possible to observe how the Deming PDCA cycle urges the educator to go through the stages of experiencing, reflecting, thinking and acting in a continuum of teaching processes related to the needs of both educators and students (in a correlated way) and to their own context, or in a holistic way. Ultimately, the PDCA cycle guides the educator to develop skills in all stages of the Kolb Experiential Cycle in order to "move freely around the learning cycle and to modify one's approach to learning based on the learning situation". It should also be noted that the understanding of the experience schematically summarized in the STP, highlights the flexibility of the educator's teaching styles (strategies 8,7 and 1). This result arises from the continuous feedback process offered by the check/reflecting stage, which allowed the educator to collect information and then formulate/modify or replace the strategies initially defined (initial QFD, strategies 1,7 and 3). The experimentation and evaluation in 
the next cycle, allowed the educator to modify her behaviour providing a "training" in learning flexibility. In this sense, it is possible to say that the approach of L'Ascolto solicits and supports the development of the educator's experiential learning. This flexibility in the educator's learning and teaching styles was achieved in compliance with the complexity of teaching, namely, in the systemic, dynamic and contextual links it possesses. Thus, L'Ascolto is presented as a holistic approach aimed at the continuous improvement of training processes and continuous learning for educators and students in a systemic, dynamic and contextual way. In this sense, it is possible to consider this approach as a pedagogical model for the continuous training and self-training of educators and students in their context of place, time and relationship.

As regards the students' performance (LO), although the response to the variation in the educator's teaching strategies was positive, in the author's opinion the data are significant but not sufficient.

Experimentation with the holistic approach of L'Ascolto would be necessary over the entire course of study. In this way, it would be possible to evaluate the effect of the flexibility in the teaching styles of all the study course's educators on student performance. Furthermore, the knowledge management and sharing system - STP (teaching styles/best practices) would facilitate the experiential development of educators in their context.

\section{References}

Akao, Y. (1990). Quality Function Deployment: Integrating Customer Requirements into Product design. Productivity Press. Cambridge, MA.

Barnard, J. (1999). Using total quality principles in business courses: The effect on student evaluations. Business Communication Quarterly, 62(2), 61-73. https://doi.org/10.1177/108056999906200206

Bielefeldt, A. R., Dewoolkar, M. M., Caves, K. M., Berdanier, B. W., \& Paterson, K. G. (2011). Diverse models for incorporating service projects into engineering capstone design courses. International Journal of Engineering Education, 27(6), 1206-1220.

Burkhalter, B. B. (1996). How can institutions of higher education achieve quality within the new economy? Total Quality Management, 7, 153-160. https://doi.org/10.1080/09544129650034909

Butler, M. G., Church K. S., \& Spencer, A. W. (2019). Do, reflect, think, apply: Experiential education in Accounting. Journal of accounting education, 48, 12-21. https://doi.org/10.1016/j.jaccedu.2019.05.001

Canboy, B., Montalvo A., Buganza, M. C., \& Emmerling, M. J. (2016). 'Module 9': a new course to help students develop interdisciplinary projects using the framework of experiential learning theory. Innovation in Education and Teaching International, 53, 445-457. https://doi.org/10.1080/14703297.2014.975150

Carpenter, B., \& Tait, G. (2001). The rhetoric and reality good teaching: a case study across three faculties at the Queensland University of Technology. Higher Education, 42(2), 191-203. https://doi.org/10.1023/A:1017514502456

Casey, R. J., Gentile, P., \& Bigger, S. W. (1997). Teaching appraisal in Higher education: An Australian prospective. Higher Education, 34(4), 459-482. https://doi.org/10.1023/A:1003042830109

Chen, C. Y., Chen, P. C., \& Chen, P. Y. (2014). Teaching quality in higher education: An introductory review on a process-oriented teaching-quality model. Total Quality Management and Business Excellence, 25(1-2), 35-56. https://doi.org/10.1080/14783363.2011.637789

Coleman, J. (1976). Difference between experimental and classroom learning. In M. Keeton, Experiential Learning: Rationale, characteristics and assessment (pp. 49-61), SanFrancisco, Jossey-Bass.

Deming, W. E. (1951). Elementary principles of the statistical control of quality. Nippon Kagacu Gigutsu Remmei: Japanese Union of Science and Engineering (JUSE).

Duff, A. (1998). Objective tests, learning to learn and learning styles: a comment. Accounting Education, 7(4), 335-345. https://doi.org/10.1080/096392898331117

Dweck, C. (2008). The perils and promise of praise. Educational Leadership, 65(2), 34-39.

Feingembaum, A. V. (1956). Total Quality Control. Harvard Business Review, Boston, 34(6), 93-101.

Felder, R. M. (1993). Reaching the Second Tier: Learning and Teaching Styles in College Science Education. Journal of College Science Teaching, 23. Retrieved from http://www4.ncsu.edu/unity/lockers/users/f/felder/public/Papers/Secondtier.html

Ford, N., \& Chen, S. Y. (2001). Matching/mismatching revisited: an empirical study of learning and teaching styles. British Journal of Educational Tecnology, 32(1), 5-22. https://doi.org/10.1111/1467-8535.00173 
Gitting, L., Taplin, R., \& Kerr, R. (2020). Experiential learning activities in university accounting education: A systematic literature review, Journal of Accounting Education, 52, 1-13. https://doi.org/10.1016/j.jaccedu.2020.100680

Haddon, F. A., \& Lytton, H. (1968). Teaching approach and the development of divergent thinking abilities in primary schools. Educational Psychology, 38(2), 171-180. https://doi.org/10.1111/j.2044-8279.1968.tb02002.x

Hayes, J., \& Allison, C. W. (1996). The implication of learning styles for training and development: a discussion of the matching hypothesis. British Journal of Management, 7, 63-73. https://doi.org/10.1111/j.1467-8551.1996.tb00106.x

Herguner, G., \& Reeves, N. B. R. (2000). Going against the national cultural grain: a longitudinal case study of organizational culture change in Turkish higher education. Total Quality Management, 11(1), 45-56. https://doi.org/10.1080/0954412007017

Honey, P., \& Mumford, A. (1986). The Manual of Learning Styles. Peter Honey Associates.

Honey, P., \& Mumford, A. (1992). The manual of learning styles (3rd ed.). Berkshire: Peter Honey Publications.

Horine, J. E., \& Hailey, W. A. (1995). Challenges to successful quality management implementation in higher education institutions. Innovative Higher Education, 20(1), 7-17. https://doi.org/10.1007/BF01228324

James, W. (1912). Essays in radical empiricism. New York, NY: Longmans, Green.

Juran, J. M. (1962). Quality Control Handbook. Mc Graw-Hill, New York.

Kogan, N. (1980). Cognitive Styles and Reading Performance. Bulletin of the Orton Society, 30, 63-78. https://doi.org/10.1007/BF02653709

Kolb, A. J., \& Kolb, D. A. (2008). Experiential Learning Theory: A Dynamic, Holistic Approach to Management Learning, Education and Development. Handbook of Management Learning, Education and Development, London.

Kolb, A. J., Kolb, D. A., Passeralli, A. M., \& Shama, G. (2014). On Becoming an Experiential Educator: The Educator Role Profile. Simulation \& Gaming, 45(2), 204-234. https://doi.org/10.1177/1046878114534383

Kolb, A. Y., \& Kolb, D. A. (2013). The Kolb Learning Style Inventory 4.0: A comprehensive guide to the theory, psychometrics, research on validity and educational applications. Boston, MA: Hay Resources Direct. Retrieved from www.haygroup.com/leadershipandtalentondemand

Kolb, D. A. (1976). Learning Style Inventory: Technical Manual. McBer, Boston, MA.

Kolb, D. A. (1984). Experiential Learning: Experience as the source of learning and development. N. J., Englewood Cliffs, Prentice-Hall.

Kolb, D. A. (1985). Learning Style Inventory and technical manual. Boston: McBer \& Company.

Kolb, D. A. (1999). Learning style inventory. version 3. The Hay Group Boston.

Kolb, D. A., \& Fry, R. E. (1975). Toward an applied theory of experiential learning. In C.Cooper, (Ed), Theories of group processes. London: Wiley Press.

Kolb, D. A., Rubin, I. M., \& McIntyre, J. M. (1971). Organizational psychology: An experiential approach. Englewood Cliffs, NJ: Prentice Hall.

Kowoser, E., \& Berman, N. (1996). Comparison of pediatric resident and faculty learning styles: implications for medical education. American Journal of Medical Sciences, 312(5), 214-218. https://doi.org/10.1016/S0002-9629(15)41818-X

Lave, J., \& Wenger, E. (1991). Situated learning: Legitimate peripheral participation. Cambridge, UK: Cambridge University Press. https://doi.org/10.1017/CBO9780511815355

Lawn, M. (1991). Social construction of quality on teaching. Evaluation and research in Education, 5(1-2), 67-77. https://doi.org/10.1080/09500799109533299

Mantos, J., Sarrico, C. S., \& Rosa M. J. (2017). The integration of quality management in higher education institutions: a systematic literature review. Total Quality Management, 28(2), 159-175. https://doi.org/10.1080/14783363.2015.1050180

Marsh, H. D., \& Roche, L. A. (1997). Making students' evaluations of teaching effectiveness effective: The 
critical issue of validity, bias, and utility. American Psychologist, 52(11), 1187-1197. https://doi.org/10.1037/0003-066X.52.11.1187

Mcdonald, E. R. (1984). The Relationship of Student and Faculty Field-dependence-independence. Congruence to Student Academic Achievement. Educational and Psychological Measurement, 44, 725-731. https://doi.org/10.1177/0013164484443022

Messick, S. (1976). Individuality in Learning. Jossey-Bass, San Francisco.

Miller, A. (1991). Personality Types, Learning Styles and Educational Goals. Educational Psychology, 11, 217-238. https://doi.org/10.1080/0144341910110302

Morin, E. (2001). I sette saperi necessari all'educazione del futuro. Raffaello Cortina Editore, Milano.

Newman, F. (1999). The trasformation of Higher Education for the new global environment. The Futures Project: Policy for Higher Education in a Changing World. Retrieved from http://www.futuresproject.org

O'Connell, B., Carnegie, G., Carter, A., de Lange, P., Hanchock, P., Helliar C., \& Watty, K. (2015). Shaping the future of accounting in business education in Australia. CPA Australia, Melbourne, Australia.

Owlia, M. S. (1996). Quality in higher education - a survey. Total Quality Management and Business Excellence, 7(2), 161-172. https://doi.org/10.1080/09544129650034918

Probst, G., Raub, S., \& Romhardt, K. (2002). Managing knowledge: Building blocks for success. New York, NY: John Wiley \& Sons Ltd.

Ramsden, P. (2003). Learning to teach in higher education. New York, NY: Taylor \& Francis Group. https://doi.org/10.4324/9780203507711

Riding, R., \& Douglas G. (1993). The Effect of Cognitive Styles and Mode of Presentation on Learning Performance. British Journal of Educational Psychology, 63, 297-307. https://doi.org/10.1111/j.2044-8279.1993.tb01059.x

Rush, G. M., \& Moore, D. M. (1991). Effect of restructuring training and cognitive style. Educational Psychology, 11(3), 309-321. https://doi.org/10.1080/0144341910110307

Sakthivel, P. B., \& Raju, R. (2006). Conceptualizing total quality management in higher education. The TQM Magazine, 16(2), 145-159. https://doi.org/10.1080/14783360600595476

Sternberg, R. J. (1997). Stili di pensiero Differenze individuali nell'apprendimento e nella soluzione di problemi. Erickson, Trento.

Verna, I. (2008). La progettazione di un intervento didattico in Economia Aziendale. Roma, Aracne Editrice.

Verna, I. (2012). Il ciclo di Deming nella didattica universitaria. Il Teaching Evaluation Model TEM, Roma, Aracne Editrice.

Verna, I. (2014). The Quality Function Deployment and the customer satisfaction. The case of universities, European Scientific Journal, Special Edition, 8, 189-202.

Verna, I. (2017). Procedimento per la progettazione, gestione, valutazione/autovalutazione e miglioramento dei processi didattici, Atto pubblico depositato presso un notaio della Repubblica Italiana.

Verna, I., \& Perozzi D. (2014). Applying TEM Model (Teaching Evaluation Model) in Academic course in accounting: a comparison across five years. European Scientific Journal Special Edition, 1(6), 330-344.

Verna, I., \& Perozzi, D. (2010, august). The Deming cycle in university teaching. The TEM Model (Teaching Evaluation Model). Poster presented at the American Accounting Association, Annual Meeting, SanFrancisco, CA.

Verna, I., \& Pizzolitto E. (2019). Using the Quality Function Deployment methodology for effective planning of theaching and learning processes. Conference Proceeding Limen, Select Paper. https://doi.org/10.31410/LIMEN.S.P.2019.77

Verna, I., Antonucci, G., Sargiacomo, M., \& Venditti, M. (2019). Listening as 'Guiding Tool' in the Continuous Improvement of University Education: A Holistic Approach. European Scientific Journal, 15(25), 57-78. https://doi:10.19044/esj.2019.v15n25p57

Verna, I., Ianni, L., D’Andreamatteo A., \& Venditti, M. (in press). Un approccio olistico alla misurazione della performance nella formazione universitaria. Un modello sperimentale: 1'Ascolto. In A. Paolini, L. Del Bene (a cura di) Monitorare la performance delle università statali e utilizzarne gli esiti per generare valore 
pubblico, GdL SIDREA, Franco Angeli.

Visser, S., McChlery, S., \& Vreken, N. (2006). Teaching Styles versus learning styles in the accounting sciences in the United Kingdom and South Africa: a comparative analysis. Meditary Accountancy Research, 14(2), 97-112. https://doi.org/10.1108/10222529200600015

Witkin, H. A. (1976). Cognitive Styles in Academic Performance and in Teacher-student Relations. In: S. Messick (ed.), Individuality in Learning, (pp. 38-72). Jossey-Bass, San Francisco, CA.

Zhang, L. (2006). Does student-teacher thinking style match/mismatch matter in students' achievement? Educational Psicology, 26(3), 395-409. https://doi.org/10.1080/01443410500341262

Note 1 L'Ascolto ${ }^{\circledR}$ is currently an experimental, multidisciplinary project of the G. d'Annunzio University that has decided to finance the creation of a web platform that reproduces the L'Ascolto ${ }^{\circledR}$ approach based on algorithms (Ida Verna, "Procedure for the design, management, evaluation/self-evaluation and improvement of teaching processes", Public deed filed with a notary of the Italian Republic, 27.01.2017). L'Ascolto ${ }^{\circledR}$ is a holistic approach to university teaching aimed at improving education and training based on the principles and methods of Total Quality Management - TQM (Feingembaum, 1956; Juran, 1962; Deming, 1951). This approach is an evolution of the Teaching Evaluation Model (TEM) based on the Deming cycle (Deming, 1951) and aimed at the continuous improvement of individual university courses (Verna, 2008; Verna, Perozzi, 2010, Verna, 2012). TEM experimentation over the years (Verna, Perozzi, 2014) has led to an integration of this approach with another Quality method (Verna, 2014), that of Quality Function Deployment (Akao, 1990). Subsequent reflections on the complexity of teaching (systemic, dynamic and contextual) and on the context in which it operates, made it possible to extend the approach to the overall teaching processes, that is, to the Course of Studies and individual teaching units considered as a single whole (Verna, 2017).

Note 2 The course targets are defined by the educator in relation to the general objectives of the course planned during the design of the course of studies after heeding the needs of the social partners. In this work, as specified in the body of the text, we limit ourselves to examining the single course unit, therefore, the specific teacher-student relationship.

\section{Copyrights}

Copyright for this article is retained by the author(s), with first publication rights granted to the journal.

This is an open-access article distributed under the terms and conditions of the Creative Commons Attribution license (http://creativecommons.org/licenses/by/4.0/). 